\title{
PEMBERDAYAAN MASYARAKAT MELALUI PENINGKATAN MUTU KESEHATAN DAN PENDIDIKAN DI DESA DUKUH
}

\author{
Suhendra ${ }^{1}$, Deddy Rachmady, Novia Handayani ${ }^{2}$ \\ suhendra@uika-bogor.ac.id \\ Dosen Fakultas Agama Islam¹, Mahasiswa KKN Kelompok 53 Tahun $2018^{2}$
}

\begin{abstract}
ABSTRAK
Kesehatan lingkungan dan Pendidikan merupakan dua hal penting yang harus diperhatikan dalam dunia Masyarakat. Kurangnya pemerataan pemahaman kesehatan dan pendidikan di masyarakat membuat kec.cibungbulang desa dukuh menjadi desa yang turun akan angka kesehatan dan pendidikannya. Peningkatan masyarakat hanya terlihat dari segi skill dan kreativitas, khususnya ibu-ibu desa dukuh yang begitu aktif dalam mempersiapkan kreativitas dalam menyambut acara besar 17 Agustus. Namun, untuk kesadaran akan lingkungan dan dunia pendidikan masih kurang. Hal tersebut bisa terlihat dari banyaknya anak-anak di bawah usia sekolah harus putus sekolah karena faktor ekonomi atau kurangnya perhatian dari orangtua terkait pentingnya pendidikan. Selain pendidikan, kesadaran masyarakat akan lingkungan masih perlu ditingkatkan lagi. Momen gotong royong warga yang seharusnya menjadi solusi akan kebersihan lingkungan dari sampah masih sedikit yang aktif untuk ikut andil dalam menjalankan program tersebut.
\end{abstract}

Kata Kunci : Lingkungan, Pendidikan, Sampah

\section{PENDAHULUAN}

\section{Kondisi Geografis}

Secara geografis, Desa Dukuh terletak di bagian Barat kabupaten Bogor. Berikut detail Geografis Desa Dukuh, kec. Cibungbulang yang menjadi sasaran KKN UIKA 2018:

\section{Batas Wilayah}

\begin{tabular}{|l|l|l|}
\hline No & Arah & Berbatasan \\
\hline 1. & Utara & Cemplang \\
\hline 2. & Selatan & Cijujung \\
\hline 3. & Timur & Cimanggu 2 \\
\hline 4. & Barat & Galuga \\
\hline \multicolumn{3}{|l|}{ Secara umum kondisi Masyarakat } \\
\hline
\end{tabular}

Desa Dukuh RW 01 yang menjadi tempat sasaran KKN kami memiliki banyak sambutan positif. Warga yang mudah bersosialisasi membuat kami mudah untuk masuk dan terjun langsung ke dalam desa tersebut. Masyarakat desa pun menyambut kami dengan tangan terbuka.

Melihat respon masyarakat yang baik, membuat kami semangat untuk menjalankan program kerja kemasyarakatan untuk membangun kembali Desa Dukuh agar bisa lebih baik ke depannya. Dimulai dari bergabung ke acara pengajian ibu-ibu yang biasa di selenggerakan setiap senin dan kamis, juga bersosialisasi langsung dengan Masyarakat sekitar untuk membentuk kedekatan antar mahasiswa dan masyarakat. Dari programprogram kemasyarakatan yang kami pilih tentunya untuk memberikan kemanfaatan bagi warga sekitar Desa Dukuh juga untuk 
memberikan pengalaman tersendiri bagi kami selaku mahasiswa.

Jadi dapat kami ambil kesimpulan bahwasanya, kondisi masyarakat Desa Dukuh terlihat baik, bersahabat dan mau menerima kami tanpa adanya konflik dari berbagai pihak. Perumusan rencana strategis dalam pengembangan Desa Dukuh yang kami telah lakukan adalah dengan menggunakan analisis SWOT (Strenght, Weakness, Opportunities, dan Threats) terhadap desa. Oleh karena itu kami mencoba menganalisis dengan hal tersebut yakni:

\section{Strenght (Kekuatan)}

Berdasarkan pengamatan yang telah kami lakukan, maka dapat diidentifikasikan beberapa factor yang menjadi kekuatan internal sebagai berikut:

a. Desa dukuh memiliki lahan pertanian dan penanaman tanaman palawija yang cukup luas beberapa hektar

b. Disamping pertanian, Desa Dukuh juga memiliki lahan pabrik peternakan pemotongan ayam dan pemancingan yang terletak di RW 01 Desa Dukuh. Lahan pabrik dan pemancingan tersebut menjadi salah satu potensi untuk meningkatkan perekonomian masyarakat yang bekerja di pabrik juga pemancingan tersebut.

c. Lingkungan masyarakat yang damai dan Indah mendukung proses pembangunan masyarakat yang terarah

\section{Weakness (Kelemahan)}

Selain memiliki berbagai kelebihan, Desa Dukuh juge memiliki kelemahan. Dari hasil identifikasi diperoleh kelemahan diantaranya:

a. Minimnya tempat pembuangan sampah sementara, sehingga sampah menjadi permasalahan yang sangat serius di Desa tersebut.

b. Minimnya sarana penunjuk arah sehingga sebagian masyarakat yang belum mengenal Desa Dukuh sulit untuk mencari lokasi Desa Dukuh tersebut

c. Kurangnya kesadaran masyarakat terkait sampah, sehingga sampah terlihat di beberapa titik tempat yang menyebabkan tercemarnya polusi udara di desa tersebut.

d. Kurangnya antusiasme masyarakat terkait pendidikan bagi anak

\section{Opportunities (Peluang/Kesempatan)}

Selain mengidentifikasi factor internal berupa kelemahan dan kelebihan, pihak desa juga harus menangkap peluang dan ancaman yang datang dari lingkungan eksternal. Adapun yang dapat diidentifikasi antara lain:

a. Bantuan penyuluhan bak sampah bagi warga masyarakat desa Dukuh dalam rangka untuk meningkatkan kesadaran masyarakat sekitar terkait kebersihan lingkungan.

b. Bantuan penyuluhan dari dinas peternakan dan kebersihan terkait limbah pabrik ayam potong yang menjadi keluhan warga masyarakat desa

c. Adanya kebijakan pembangunan desa dari pemerintah yang mana desa diberikan dana yang besar untuk membangun desa tersebut lebih dipotimalkan dan diperuntukkan untuk infrastrukrut daerah-daerah di desa untuk kepentingan masyarakat desa tersebut, seperti perbaikan fasilitas umum, dan bedah rumah bagi keluarga kurang mampu

d. Bantuan penyuluhan kesehatan dari dinas kesehatan untuk warga desa Dukuh 


\section{Threats (Ancaman)}

Hasil identifikasi ancaman untuk Desa Dukuh antara lain:

1. Sumber air yang sulit akibat saluran irigasi yang bermasalah. Hal ini tentunya berakibat dengan sulitnya warga masyarakat untuk mendapatkan sumber air yang mencukupi
2. Lokasi desa yang dipelosok membuat terancamnya tingkat keamanan desa dari pencurian dan tindakan kriminal yang meresahkan warga Desa sekitar.

3. Selokan yang kurang diperhatikan. Hal ini tentunya akan berakibat dengan meluapnya air di dalam selokan tersebut. Khususnya saat musim hujan.

\section{METODE PENGABDIAN}

Tahapan pelaksanaan untuk kegiatan ini sebagaimana terlihat pada bagan sebagai berikut:

Bagan 3.1. Bagan Alir Pelaksanaan

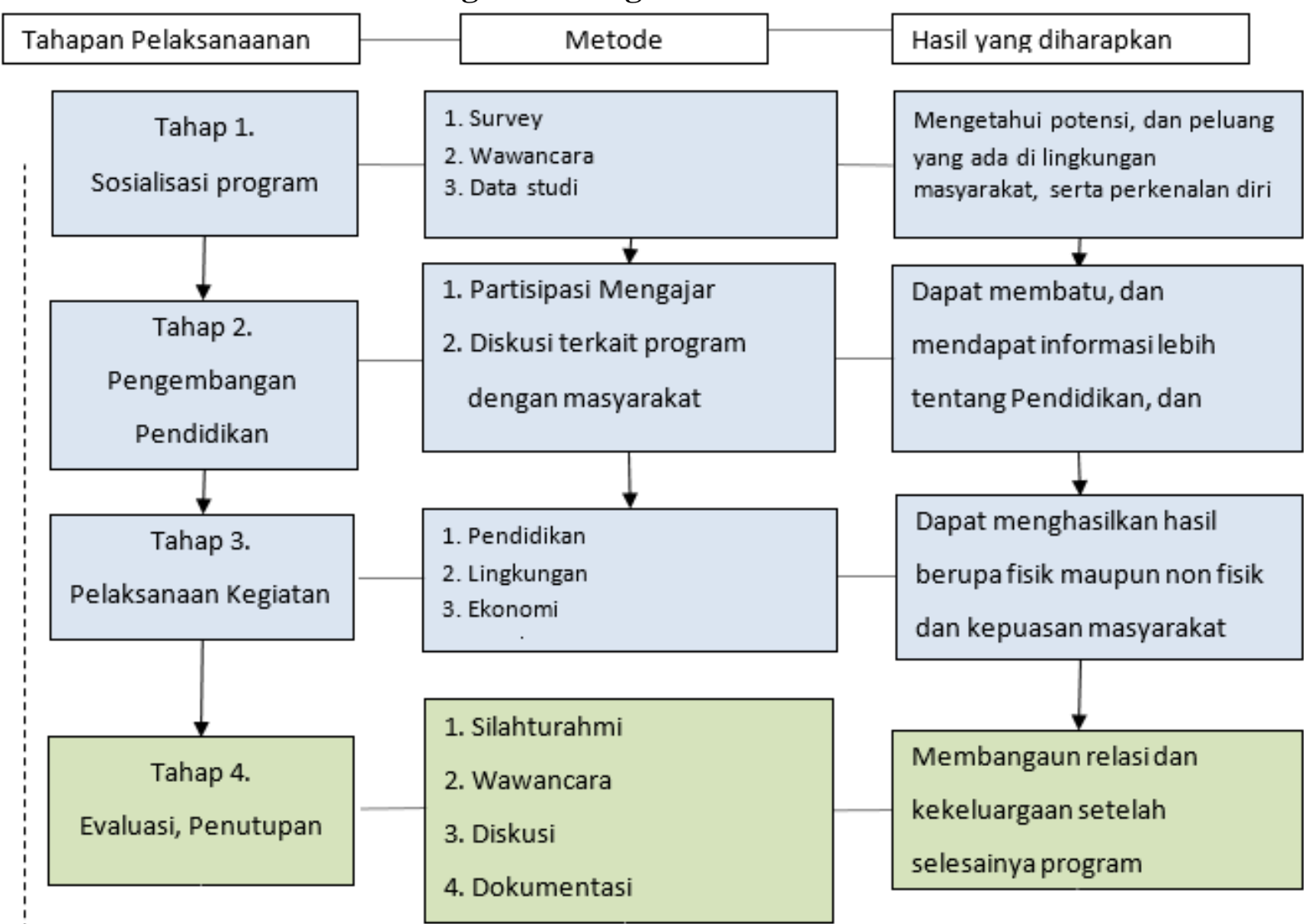

\section{Metode Pendekatan}

Pendekatan yang digunakan pada kegiatan ini adalah dengan pendekatan geografi sosial, dimana pendekatan ini terdiri dari 3 aspek: (1) Keruangan, (2) Kelingkungan, dan (3) Kompleks Wilayah. Ketiga aspek tersebut dilihat dari sudut pandang geografi untuk menganalisis dan bagaimana solusi untuk kehidupan sosial masyarakat desa waru. Maka diperlukan strategi dalam pelaksanaanya dengan beberapa pendekatan yang strategis, diantaranya:

a. Pendekatan berdasarkan karakter masyarakat, yakni pembinaan yang dilakukan akan disesuaikan dengan karakter masyarakat. Joyce dan Weil (1996) mengungkapkan bahwa model pendidikan yang relevan dengan perilaku sosial dan nilai adalah dengan banyak memberikan permainan peran. Hal ini dilakukan untuk memberi 
pengalaman riil kepada peserta didik tentang sesuatu yang dilakukan atau dirasakan oleh orang lain. Memang, dalam prakteknya, tidak seluruh aspek harus menggunakan permainan ini. Dalam beberapa hal, terdapat kegiatankegiatan yang hanya golongan tertentu untuk melakukannya. Sejalan dengan konsep Joyce dan Weil, cooperative learning yang digagas Slavin (2005) dapat digunakan untuk membangun kesadaran toleransi masyarakat. Hal ini karena penekanan dari konsep pendidikan ini adalah kerjasama yang merupakan urat nadi toleransi. Dengan demikian, model pendidikan yang akan dibangun menggunakan dua konsep utama yaitu role playing model dan cooperative learning model.

b. Pendekatan organisasi, yaitu pendekatan dimana sebagian kegiatan diorganisir dan bekerja sama dengan lembaga pendidikan dan lembaga masyarakat yang ada di desa Situ Daun .

Dimana dalam pelaksanaan untuk mengetahuhi bagaimana langkah yang perlu ditempuh dan luarannya menjadi solusi untuk pengembangan lingkungan dan pendidikan masyarakat sekitar, oleh karena itu kami memerlukan metode pengambilan data, metode yang digunakan dalam hal ini adalah :

1. Wawancara

Proses memperoleh penjelasan untuk mengumpulkan informasi dengan menggunakan cara tanya jawab bisa sambil bertatap muka ataupun tanpa bertatap muka yaitu melalui media telekomunikasi antara pewawancara dengan yang diwawancarai, dengan ataupun tanpa pedoman. Pada hakikatnya wawancara merupakan kegiatan untuk memperoleh informasi ecara mendalam tentang sebuah isu atau tema yang diangkat dalam penelitian. Atau, merupakan proses pembuktian terhadap informasi atau keterangan yang telah diperoleh lewat teknik yang lain sebelumnya (Sujarweni: 2015).

\section{Studi Dokumen}

Metode pengumpulan data kualitatif sejumlah besar fakta dan data tersimpan dalam bahan yang berbentuk dokumentasi. Sebagian besar data berbentuk surat, catatan harian, arsip foto, hasil rapat, jurnal kegiatan dan lain sabagainya. Data jenis ini mempunyai sifat utama tak terbatas pada ruang dan waktu sehingga bisa dipakai untuk menggali informasi yang terjadi dimasa silam. (Sujarweni: 2015).

\section{Partisipasi Masyarakat dalam Pelaksanaan Program}

Partisipasi masyarakat yang dapat dilakukan dalam kegiatan ini adalah sebagai berikut:

1. Bersedia untuk diwawancarai terkait dengan berjalannya program.

2. Mempersiapkan tempat untuk penyuluhan lingkungan dan pendidikan.

3. Menjadi rekan kerjasama dalam beberapa kegiatan.

4. Partisipasi dan memeriahkan beberapa program.

5. Bersama-sama dengan Tim Pengusul melakukan kegiatan dan berdiskusi terkait berjalannya program pengembangan pendidikan dan lingkungan

\section{Langkah Evaluasi}

Evaluasi yang akan dilakukan terdiri dari:

1. Evaluasi Masukan meliputi pertimbangan tentang sumber dan 
strategi yang diperlukan untuk mencapai tujuan terlaksananya program. Informasi-informasi yang terkumpul selama tahap penilaian hendaknya dapat digunakan untuk menentukan sumber dan strategi didalam keterbatasan dan hambatan yang ada.

2. Evaluasi proses, yang terkait dengan perencanaan, pelaksanaan dan monitoring kegiatan. Evaluasi proses akan dilakukan setiap pekan bersama dengan seluruh anggota KKN 29.

3. Evaluasi Hasil penilaian dalam mengukur keberhasilan pencapaian program bersifat fisik maupun non fisik, penilaian tersebut dikembangkan dan diadmistrasikan. Sehingga data yang dihasilkan sangat berguna bagi anggota dan masyarakat setempat dalam menentukan apakah program, diteruskan, dimodivikasi atau dihentikan.

\section{REALISASI PROGRAM}

Program kerja KKN kelompok 29 yang sudah terlealisasi adalah sebagai berikut:

\section{Bidang Pendidikan}

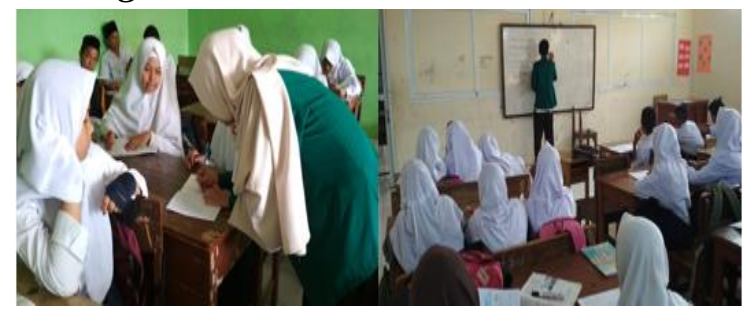

a. Pengabdian di Sekolah MTS Darul Ihsan Desa Dukuh

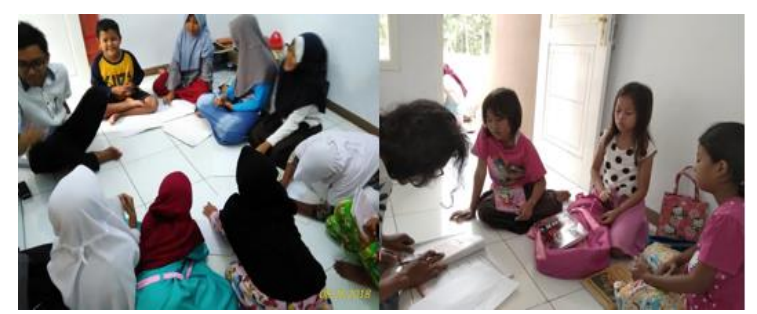

b. Bimbingan Belajar Bahasa Inggris

c. Tahsin dan Tahfidz

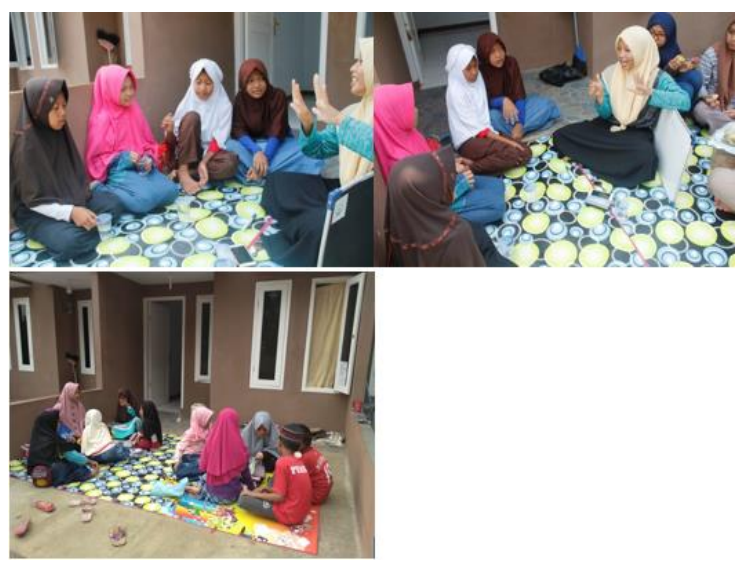

d. Bimbingan Belajar Matematika

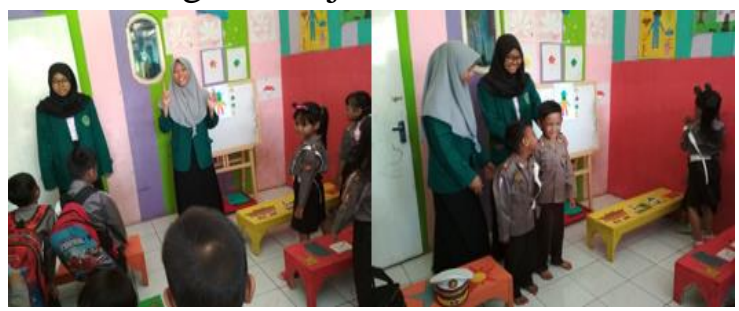

e. Pengabdian di Sekolah PAUD

f. Bimbel PR

\section{Bidang Kesehatan}

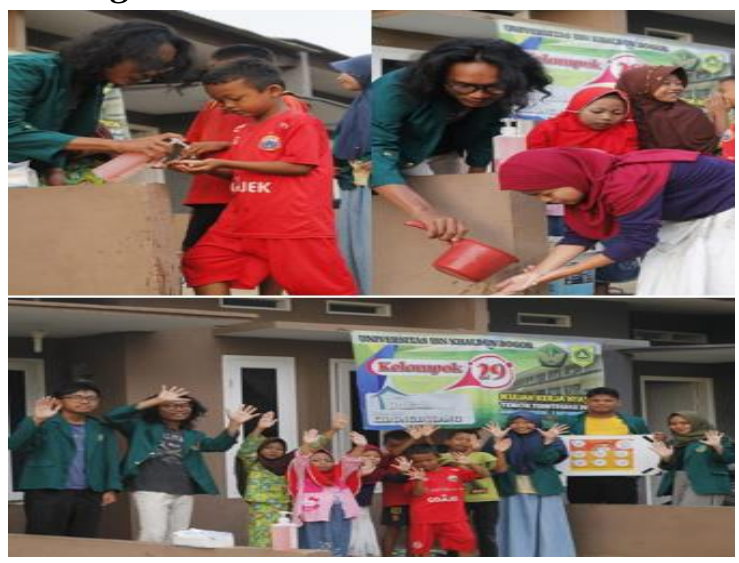

a. Penyuluhan Pola Hidup Bersih dan Sehat (PHBS)

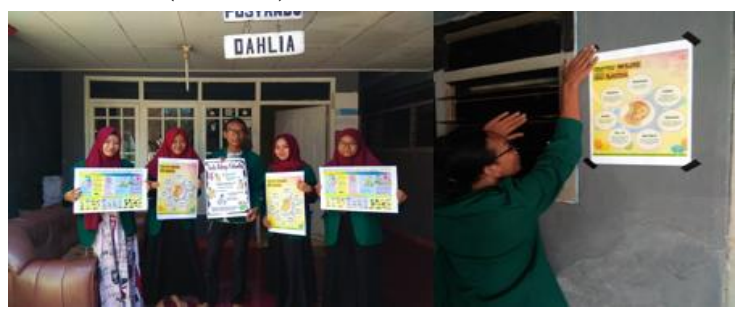

b. Pemasangan Poster di Posyandu Dahlia 

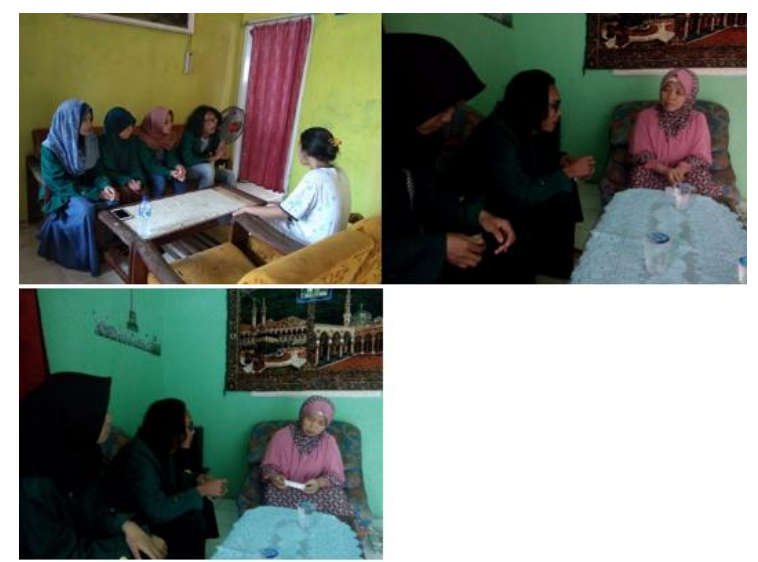

c. Penyuluhan kesehatan Ibu dan Anak

\section{Bidang Ekonomi}

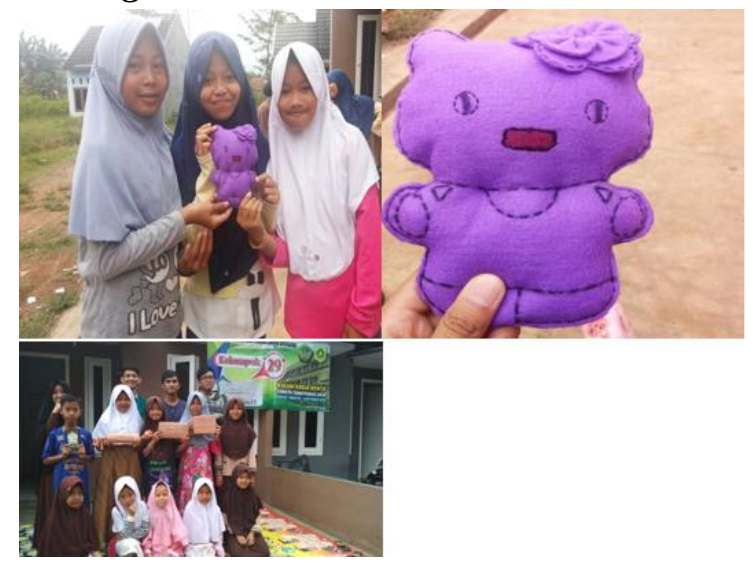

a. Membuat loka Karya

\section{Bidang Lingkungan}

a. Penyediaan Bak Sampah di RW 02

Penyediaan bak sampah tersebut terbagi menjadi 2 unit bak sampah bagi masingmasing rt. Karena di desa dukuh tersebut, memiliki 2 rt. Dan kami mengabdi di RW 02 yang memiliki 4 RT.

b. Penyediaan Al-Qur'an sebanyak 50 buah yang masing-masing dibagi menjadi 10 buah untuk dierikan ke tempat-tempat pengajian, masjid dan mushola (Penyerahan kepada Ketua RW 01 Desa Dukuh)

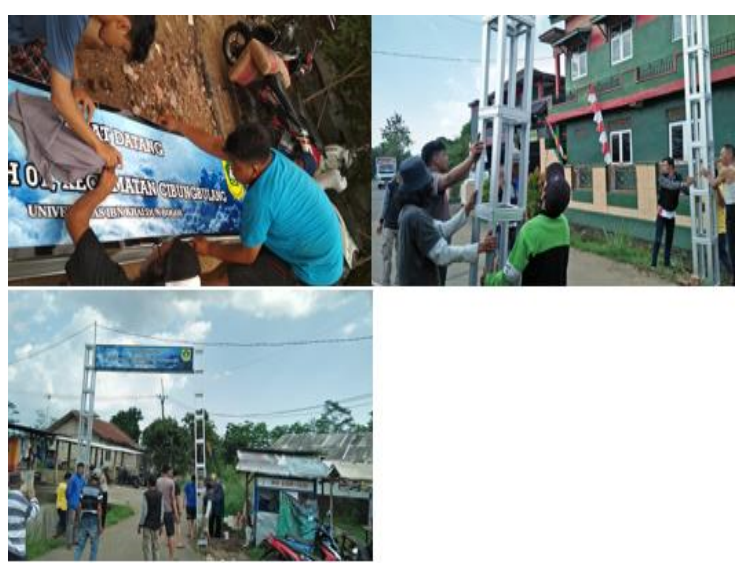

c. Penyediaan Gapura sebagai sarana penunjuk arah menuju Desa Dukuh

\section{KESIMPULAN}

Masyarakat Desa Dukuh RW 02 sangat antusias mengikuti program kegiatan yang telah dijalankan, khususnya dikalangan anak-anak. Banyak masyarakat turut andil membantu dalam pelaksanaan program yang telah ditentukan, sehingga program bisa berjalan dengan baik dan lancar. Setelah menjalankan program KKN Terintegrasi di Desa Dukuh, masyarakat mendapatkan beberapa dampak positif yang dihasilkan

\section{SARAN}

Berdasarkan kesimpulan yang telah dipaparkan, maka kami rekomendasikan perlu adanya perhatian lebih dari masyarakat sekitar terkait pendidikan anakanak. Hal tersebut dilakukan guna untuk meningktakan mutu pendidikan di Desa Dukuh juga untuk melahirkan generasi penerus bangsa yang kuat akan ilmu pengetahuan.

Adapun rekomendasi yang dapat kami ajukan adalah sebagai berikut: 
Bidang Pendidikan.

a. Perlunya perhatian lebih dari orang tua terhadap kemajuan pendidikan anak.

b. Adakan perpustakaan keliling agar motivasi anak untuk belajar meningkat.

c. Adakan penyuluhan secara berkala baik itu pada peserta didik dan orangtua untuk meningkatkan motivasi pendidikan.

d. Adakan kursus komputer dan bahasa asing.

e. Adakan kelompok belajar kecil bagi peserta didik.

Bidang kesehatan dan Lingkungan

a. Adakan Puskesmas

b. Berdayakan kembali keluarga sadar kebersihan dan kesehatan

c. Adakan pembinaan PKK secara berkala agar lebih professional dalam meningkatkan kesehatan

d. Melakukan pengelolaan sampah secara terstruktur

e. Adakan tempat pembuangan sampah sementara

f. Aakan kerja bakti rutin

Bidang Kewirausahaan

a. Adakan pelatihan untuk warga dalam mengolah sumber daya yang ada secara rutin.

b. Tumbuhkan jiwa kewirausahaan pada setiap warga.

c. Adakan penyuluhan pemanfaatan limbah rumah tangga.

d. Adakan program pengolahan hasil pertanian agar menjadi produk yang berdaya dan bernilai jual tinggi.

\section{REFERENSI}

Administrasi profil desa

Eska Perdana Prasetya (2016), The Effect of Students' Perception on School Environment and Self-discipline towards Their Achievement in Learning English: A Survey at a Private Vocational School in Bogor. E-Journal Universitas Ibn Khaldun Bogor

Joyce, Bruce dan Weil, Marsha. (1996). Models of Teaching. Boston: Allyn and Bacon.

Sujarweni (2015), Metode Penelitian Bisnis dan Ekonomi, Pustakabarupress, Yogyakarta.

Slavin, R.E. (2005). Cooperative learning: theory, research and practice. London: Allyn and Bacon. 